\title{
FIFTH INTERNATIONAL CONGRESS
}

\section{OF LEPROSY.}

\section{INTRODUCTION.}

(Abstracted from the Report of Mr. Perry Burgess,

Chairman, United States Delegation.)

The invitations to the Congress were issued by the Cuban government through diplomatic channels to all countries with which Cuba maintains official relations. Those countries represented were as follows:

\begin{tabular}{|c|c|c|c|c|c|c|c|}
\hline \multicolumn{2}{|c|}{ Country } & & $\begin{array}{l}\text { imber of } \\
\text { elegates }\end{array}$ & \multicolumn{2}{|c|}{ Country } & \multicolumn{2}{|c|}{$\begin{array}{l}\text { Number of } \\
\text { Delegates }\end{array}$} \\
\hline Argentina & $\ldots$ & $\cdots$ & I5 & Guatemala & $\ldots$ & $\ldots$ & I \\
\hline Bahamas & $\ldots$ & $\ldots$ & I & Hawaii & $\ldots$ & $\ldots$ & 2 \\
\hline Belgian Cor & go & $\ldots$ & 4 & India ... & $\ldots$ & $\ldots$ & 2 \\
\hline Bermuda & $\ldots$ & $\ldots$ & I & Martinique & $\ldots$ & $\ldots$ & I \\
\hline Brazil & $\ldots$ & $\ldots$ & 27 & Mexico & $\cdots$ & $\ldots$ & I5 \\
\hline British Gui & na & $\ldots$ & I & Nigeria & $\ldots$ & $\ldots$ & I \\
\hline China & $\ldots$ & $\ldots$ & 2 & Norway & $\ldots$ & $\ldots$ & I \\
\hline Colombia & $\ldots$ & $\ldots$ & 3 & Panama & $\ldots$ & . & I \\
\hline Cuba ... & $\ldots$ & $\ldots$ & 73 & Peru ... & $\ldots$ & $\ldots$ & I \\
\hline Dominican & Republi & c. & I & Philippines & $\ldots$ & $\ldots$ & 2 \\
\hline Dutch Guia & na & $\ldots$ & I & Portugal & $\ldots$ & $\ldots$ & 2 \\
\hline East Africa & $\ldots$ & $\ldots$ & I & Puerto Rico & $\ldots$ & $\ldots$ & I \\
\hline England & $\ldots$ & $\ldots$ & 5 & South Africa & & $\ldots$ & I \\
\hline Ecuador & $\ldots$ & $\ldots$ & I & Spain & $\ldots$ & $\ldots$ & IO \\
\hline Egypt & $\cdots$ & $\ldots$ & I & Sweden & $\cdots$ & $\cdots$ & I \\
\hline Fiji $\quad \ldots$ & $\ldots$ & $\ldots$ & I & Trinidad & $\ldots$ & $\ldots$ & I \\
\hline France & $\ldots$ & $\cdots$ & 5 & Unitèd State & & $\ldots$ & 30 \\
\hline Germany & $\ldots$ & $\ldots$ & I & Venezuela & $\ldots$ & $\cdots$ & 3 \\
\hline
\end{tabular}

Total Number of Countries Represented: Thirty Six

Total Number of Delegates: Two Hundred \& Twenty

Total Number of Official U.S. Delegates: Five

Total Number of Other U.S. Delegates: Twenty Five

\section{Meeting Place of the Congress}

The sessions of the Congress were held at the Municipal School "Valdes Rodriguez," Calle 6, Vedado, Havana. In this three storey building the offices and services of the Congress were amply 
housed. Dormitories and a restaurant were provided at a cost of about $\$ 2.00$ per day for those who wished to take advantage of this reasonable cost. This feature of the arrangement was very popular. The Coca Cola company supplied Coca Cola without charge to the delegates of the Congress.

The various commissions met in the large lecture rooms of the school and similar space was provided for the scientific and commercial exhibits. One room was set aside for the press.

\section{Registration Place}

Presentation of credentials took place Saturday morning, April 3. Each member of the Congress registered and received his number on the list and was given a folder containing his registration card, a map of Havana, the Congress medal, its scientific program, and invitations for the various social events and other material, including cigars.

\section{Categories of Congress Members}

I. Official delegates of the governments - those delegates designated and duly accredited by the various governments in response to the official invitation through diplomatic channels by the Republic of Cuba.

2. Other foreign delegates-those delegates representing the International Leprosy Association, private entities interested in the problem of leprosy and individuals interested in this disease but not representing any such entity.

3. Official Cuban delegates-those who were designated by the Cuban Ministry of Public Health or Cuban provincial governments, municipalities or medical departments.

Official Languages

$$
\begin{aligned}
& \text { English } \\
& \text { French } \\
& \text { Portugese } \\
& \text { Spanish }
\end{aligned}
$$

Summaries of the papers presented at the Congress were translated into the four official languages and published in a booklet which was distributed to each member.

An information room was provided in which there were interpreters for the above mentioned languages.

This was the first International Conference for Leprosy at which the facilities for simultaneous interpretation were provided. Several of the staff who had served in this capacity at the United 
Nations Conference on Trade and Employment in Havana remained for this purpose.

\section{OfFicial EMBLEM}

The official emblem adopted by the, national organizing committee as Congress seal and engraved on the commemorative medal, consisted of a circle, with the Cuban coat-of-arms in relief, surounded by two other concentric circles between which appears the following inscription: " V Congreso Internacional de la Lepra, Habana, Cuba, Abril, I948.' This medal hung from a threecoloured ribbon (white, blue and red, colours of the Cuban flag) which in turn hung from a pin holding a card with the name of each member of the Congress, his nationality, and his number.

\section{Commemorative Stamp}

The Cuban government, in order to emphasize the importance of the International Leprosy Congress, ordered the issuance of a commemorative postage stamp, which is a two-cent stamp bearing a portrait of Armauer Hansen (the Norwegian doctor who isolated the leprosy bacillus) on a typical Cuban landscape background, decorated by a triangular Cuban flag in its upper right-hand corner while its lower left-hand corner bears the caduceus symbolizing medicine and a legend reading: "Correos, Cuba. Congress Internacional de la Lepra. Habana, I948." Under the portrait in small type: "Armauer Hansen."

The sale of the issue of the commemorative stamp began on the day of the inauguration of the Congress.

\section{Social Evints of THE CONGRiss}

The national organizing committee planned an extensive program of social events and functions, namely: A visit to the Hon. President of the Republic, Dr. Ramon Grau San Martin at the Presidential Palace, who gave the address of welcome; response by Dr. Floriano de Mello of Portugal.

Reception for members of the Congress offered by the Hon. Minister of Public Health and Social Service, Dr. Ramiro de la Riva, who gave the address of welcome; response on behalf of the delegates was given by Mr. Perry Burgess, Chairman of the U.S. Delegation. Palace.

Reception given by the Mayor of Havana at the Municipal

Country lunch given by the Governor of the Province of Havana at restaurant " Rio Cristal."

Evening concert of Cuban music at the Radio Center. 
Cocktail party given by the National Medical Association.

Trip to Varadero Beach with lunch at "Club Kawama."

Tea given by the Cuban Society of Dermatology \& Syphilology at the "Club de Profesionales de Cuba."

\section{Social Clubs}

The national organizing committee obtained the co-operation of the Casino Espanol de la Habana, the Jaimanitas Biltmore, the Club Nautico de Marianao, Club de Profesionals de Cuba, and the Miramar Yacht Club, which extended their social privileges to the foreign delegates to the Congress. Each delegate was presented with a formal invitation in his name on an engraved card

\section{FINAL PLENARY SESSION}

\section{OFFICERS}

President

Associate President

General Secretary

Assistant Secretary
Dr. Alberto Oteiza Setien

Dr. H. W. Wade

Dr. I. Ferrer

Dr. E. Muir

I. Reports of the Commissions were read and approved.

2. Invitations were presented for the meeting of the next Congress in 1953 as following:-

(a) An official invitation from the Indian Government was presented to hold the next Congress in Calcutta, India.

(b) No official invitation was presented from the Government of Spain but a petition was signed by approximately 50 delegates from Spain and various Latin American countries that the next Congress be held in Madrid. This suggestion was adopted by an overwhelming majority.

\section{Adjournment.}

3. Mr. Perry Burgess addressed the Congress for the purpose of expressing on behalf of the foreign delegates and delegation appreciation to the Cuban Government and the doctors of the Organizing Committee and others for the courtesies and assistance rendered to the Congress. Prior to his address Mr. Burgess announced that the Leonard Wood Memorial Photographic Department would give complimentary prints to each delegate photographed individually and prints of general pictures taken outside of the building. 
GENERAL MEETING OF THE INTERNATIONAL LEPROSY ASSOCIATION

A meeting of the International Leprosy Association was held immediately following the final Plenary Session of the Congress. Dr. H. W. Wade presided.

I. The General Secretary-Treasurer, Dr. Ernest Muir, presented a report covering the activities of the official organ of the Association, "The International Journal of Leprosy," and the status of membership.

2. Treasurer's Report (Dr. Muir).

3. Editor's Report (Dr. Wade).

4. The following resolution was presented and unanimously adopted:

"This Association places on record its sincere and grateful thanks for the contribution the Leonard Wood Memorial (American Leprosy Foundation) has made to the cause of Leprosy ever since the inauguration of the International Leprosy Association. Without the generous aid of the Memorial it would have been impossible to organise the Association or publish the International Journal. If it had not been for the continued financial help of the Foundation and the work of Dr. Doull and Dr. Bancroft and her staff, the Journal would have ceased during World War II. The help, advice and financial aid of the Memorial has made this Congress possible.

Our thanks are extended to Mrs. Burgess and the Photographic Committee of the Memorial for the excellent conbution which has been made in clinical photography. The advice given and the promise that the Committee will help workers in all countries in this most important field, is deeply appreciated."

5. The following proposal for amendment of the Constitution was passed:

"Certain members of the Association have expressed the opinion that Mr. Perry Burgess, President of the Leonard Wood Memorial, who has rendered exceptional service to the Association since its inception, especially in connection with support of the publication of the International Journal of Leprosy, should be made a full member. The part 
of Section 4 of the Constitution which bears on this matter reads as follows: "Regular membership shall be limited to persons with recognized medical degrees, and those with other scientific qualifications who are, or have been actively connected with" leprosy work."

It is hereby moved:

(a) that the foregoing sentence be amended to read as follows: "Regular membership shall be limited to persons with recognized medical degrees; those with other scientic qualifications who are or have been actively connected with leprosy work, and, in exceptional cases, others who have rendered signal service to the Association."

(b) that under this provision Mr. Perry Burgess and Cora Burgess be declared a regular member of the Association.

6. A statement was given regarding the World Health Organization.

7. It was resolved that the following amendment to the Constitution be added:

\section{"9A Affiliated Organizations}

The Association shall seek affiliation of scientific and other societies and organizations working in leprosy which are approved by the Council.

Resolved that it is advisable to establish relations with the World Health Organization and that the President and General Secretary be empowered to get in touch with representatives of the World Health Organization with suggestions:

(a) that the International Leprosy Association be recognised by the World Health Organization as its advisory body regarding leprosy, and

(b) that the Interim Commission should invite the International Leprosy Association to send a representative to the first meeting of the Assembly."

8. An amendment regarding the tenure of office and officers was made. Dr. Wade, President, and Dr. Muir, Secretary, were re-elected for the next five years. 


\section{REPORT OF THE COMMITTEE ON THERAPY.}

\section{INTRODUCTION.}

From opinions expressed at the Rio de Janeiro Conference in I946, and at this present International Congress, it is evident that much progress has been made in the treatment of leprosy since the Congress held in Cairo I938. Advances have been seen with respect to both the introduction of the sulphone group of drugs and the employment of hydnocarpus (chaulmoogra) oil in increasing dosages.

While the therapeutic activity of those drugs is evident, their action on the causal organism appears to be slow. It is therefore urged that further investigations be encouraged, for the purpose of increasing the effectiveness of these remedies.

It is considered advisable to lay down general directions with regard to the administration of remedies in accepted use in the therapy of leprosy.

\section{Derivatives of Diamino-Diphenyl-Sulphone.}

It is affirmed that the drugs of the sulphone group satisfy the conditions enumerated under the heading " Minimal Therapeutic Requirements" (see Research).

Existing evidence shows that these drugs are of great value in lepromatous leprosy, and many workers are of the opinion that they offer the best available therapy in this condition. Their use in cases of that type is therefore recommended. These drugs are particularly effective in moderately advanced and advanced cases: and they are of great value with respect to lesions of the nose and throat. Eye lesions frequently improve. Clinical improvement is noted first; bacteriologic improvement is much slower. Changes in the morphology of M. leprae accompany the clinical improvement.

It is the opinion of this Congress that the sulphones are the present drugs of election for the treatment of leprosy.

Sulphone Drugs in Use.

The drugs used are, in chronologic order, promin (promanide), diasone (diamidine) and sulphetrone. The intrinsic bacteriostatic efficacy of these drugs may be regarded as identical, so that similar effects may be expected from equivalent tissue concentrations. Systematic study has not yet been sufficient to permit dogmatic statements regarding dosage. The dosage schedules used in tuberculosis have in general been recommended, and the following are suggested as suitable. 
Promin (diamino-diphenyl sulphone dextrose soclium sulphonate).- In adult patients in good general condition and with a normal blood picture, an initial dose of $2 \mathrm{gm}$. in $5 \mathrm{cc}$. of solution is given intravenously daily. This dose should be increased after one to two weeks by I cc. daily until a dose of $\mathrm{T} 2.5 \mathrm{cc}$. is reached. The dosage for children depends on age, weight, general physique and individual tolerance. The drug should be administered daily for from one to three months, followed by a rest period of from one to two weeks, after which treatment is resumed. The dosage and the length of the rest periods may be modified in accordance with the requirements of the individual patients.

Diasone (disodium formaldehyde sulphoxylate of diaminodiphenyl sulphone).-The following dosage is suggested:

Ist week: $0.3 \mathrm{gm}$. (I tablet) daily for 6 days, one day of rest. 2nd week: $0.6 \mathrm{gm}$. ( 2 tablets) daily for 6 days, one day of rest. 3rd week: $0.9 \mathrm{gm}$. (3 tablets) daily for 6 days, one day of rest. In the fourth week and thereafter the dosage may be increased up to a maximum of six tablets ( $\mathrm{I} .8 \mathrm{gm}$.) a day if tolerated; the dosage should be modified according to the tolerance of the individual. A rest period of one to two weeks should be allowed after every two months of treatment.

Sulphetrone (tetrasodium 4:4'-bis y- phenylpropylaminodiphenyl-sulphone- $\mathrm{d}: \mathrm{y}: \mathrm{d}^{\prime}: \mathrm{y}^{\prime}:$-tetrasulphonate).—This drug is freely soluble and available for parenteral or oral use. A concentration of $5 \mathrm{mgm}$. per Ioo cc. of blood in ambulatory patients is recommended. This concentration is usually obtained in adults by daily total doses of 3 to $6 \mathrm{gm}$. given orally. A suitable initial dose is $0.5 \mathrm{gm}$. three times daily with, at intervals, $0.5 \mathrm{gm}$. increments of the total daily dose until the required amount is reached. Suitable doses for children appear to be $\mathrm{I} .5$ to $3 \mathrm{gm}$. daily. The drug should be given continuously for six months when a rest period may be allowed, depending on the tolerance of the patient.

Toxicity of the Sulphone Drugs.

All sulphone drugs are potentially haemotoxic. Anaemia is produced, which may appear soon after the first administration. This condition varies in degree in different individuals, and may necessitate the interruption of treatment. In most cases however some degree of tolerance develops and the blood tends to return to normal. Sulphone medication should be accompanied by continuous administration of iron and vitamin $B$ complex: liver extract and thiamine chloride should also be used.

Certain phenomena in leprosy appear or are exacerbated at some stage of sulphone therapy. These may be characterised by 
acute skin reactions, sometimes called erythema nodosum leprosum, and also by iritis. These phenomena may indicate an increase or decrease of closage, or a temporary suspension of the treatment.

Drug sensitivity occurs, though infrequently. Its incidence appears to be less where adjuvant vitamin B therapy is given. Should sensitivity occur, the drug should be discontinued at once.

Laboratory Control.

In view of the haemotoxic action of the sulphones it is desirable that their use should be subject to adequate laboratory control. It is appreciated that absorption and excretion vary considerably.

Patients in whom inadequate renal function is suspected should from time to time be subjected to routine urine tests, and occasional blood-urea estimations.

Derivatives of Hydnocarpus (Chaulmoogra) Oil.

It is the opinion of many workers that hydnocarpus (chaulmoogra) oil and its derivatives are effective in lepromatous leprosy, and that the maximum benefit is seen when these remedies are used in adequate and regular dosage. Failure of hydnocarpus oil and its derivatives is most often due to inadequate dosage and irregular administration. The preparations in general use are $(a)$ the pure oil with $0.5 \%$ to $4 \%$ creosote, and $(b)$ the ethyl esters, with $0.5 \%$ to $4 \%$ creosote or $0.5 \%$ iodine.

It is increasingly evident that the greatest benefit results from high dosage ( 15 to $25 \mathrm{cc}$. weekly), given regularly and divided between the subcutaneous, intramuscular, and intradermal routes. The maximum dose ultimately to be used depends on individual tolerance. Some patients are able to begin with relatively large doses and to continue even up to 40 to $50 \mathrm{cc}$. per week. Others cannot tolerate more than Io c.c., while in some the maximum dose must be still lower. The patient's tolerance can frequently be increased by careful regulation of dosage. In this connection the quality of the oil or esters is of great importance.

It is recommended that the maximum dosage of 15 to 25 c.c., or more if considered advisable, be reached as quickly as possible.

While some authorities consider that large doses can be given despite reactions, it is usually recommended that when that condition appears the amount given should be reduced or the treatment suspended, depending upon the severity of the reaction. Similar reduction or cessation of treatment may be necessary if there is local reaction or increase in the activity of eye lesions. Rest periods of fifteen days may be advised after every three and a half months' treatment. 
Supplementary Measures.

While it is advisable to use hydnocarpus (chaulmoogra) or sulphone therapy in leprosy, it would be unfortunate if the generally accepted treatment were confined to those drugs, without due attention to other remedial measures. The following are therefore particularly emphasised.

Alleviation of disabilities and deformities.

Physical and occupational therapy.

Attention to trophic conditions and treatment of enlarged and painful nerves.

Treatment of ocular, bucco-pharyngeal, laryngeal and nasal conditions.

Plastic and orthopœdic surgery.

Relief of reactional conditions in all types of the disease. General attention to the social, psychological and spiritual environment of the patient.

\section{RESEARCH.}

Modern research has opened up new avenues of attack against M. leprae. One of these may be the use of antibiotics. The importance of further investigation of chemotherapeutic agents and methods is stressed.

Selection of cases.-In therapeutic experiments the following points require special attention. Adequate numbers of moderately advanced lepromatous, lepromin-negative cases should be chosen. They should be cases which have either failed to respond to hydnocarpus or have had no previous treatment.

Tuberculoid, and atypical or intermediate cases, which often show spontaneous remission, should not be included in the evaluation of results.

Minimal therapeutic requirements.-It is considered that the following are the minimal therapeutic requirements in clinical research:

(a) There should be direct or indirect evidence of antibacterial action of the drug against mycobacterial diseases.

(b) The drug must be capable of effective use without causing toxic effects or irreversible physiological changes.

(c) There must be freedom from undue discomfort when the drug is administered.

(d) There must be acceptable clinical and bacteriological evidence of suppression or regression of the disease; and a visible beginning of this change niust be seen within twelve months. 
Therapentic agents needing further investigation.-Injectable sulphones, para-amino salicylic acid, sodium sulphoxylate derivatives (rongalite), streptomycin, gorli oil, combinations of therapeutic agents, anti-histamine drugs.

Regarding injectable sulphones, attention has been drawn to the possibility that diamino-diphenyl-sulphone and its derivatives may become concentrated in certain tissues of the body (for example, the skin, liver, etc.) and that, by giving parenteral medication in the form of subcutaneous injections, satisfactory concentrations of the drug in the blood and skin can be maintained. Investigations should be continued in an endeavour to confirm this finding, and to ascertain whether by means of injections of a suspension of the parent substance, or of emulsions of water-soluble derivatives, a lesser quantity of the drug can be used. If so, the administration of sulphones may be made less costly and thus available to larger numbers of people.

Both para-amino salicylic acid and sodium sulphoxylate (rongalite) appear to be worthy of further research.

While investigations with streptomycin have not as yet been encouraging, it is considered advisable to pursue these inquiries further.

It has been claimed that gorli oil, related to hydnocarpus oil, has a therapeutic effect in leprosy. In view of the importance of this oil in certain parts of Africa, this matter should be further investigated.

Emphasis has been laid during this Congress on the possible additive effects of combining the sulphones with hydnocarpus (chaulmoogra) oil or with antibiotics known to be effective against mycobacteria.

As has been pointed out, the administration of the sulphones is liable, in a proportion of cases, to result in certain skin reactions of erythema nodosum nature. It has been claimed that certain antihistamine drugs have the property of controlling and even aborting these reactions. Should these observations be confirmed, one of the most serious drawbacks to sulphone therapy would be overcome.

\section{Control of Therapeutic Agents in Leprosy.}

In view of the potential toxic effects of the sulphones, and of the necessity for a carefully regulated schedule of dosage, it is felt that the use of these drugs in leprosy should be subject to careful control. They should be sold only on medical prescription.

It is hoped that the cost of these drugs will be reduced so that they may be made more generally available. 


\section{REPORT OF THE COMMITTEE ON EPIDEMIOLOGY ANI) CONTROL.}

\section{INTRODUCTION.}

The two matters of epidemiology and control of leprosy are treated separately. Nevertheless, they are intimately bound up together in that (a) the discoveries of the one directly influence the other and conversely; and in that $(b)$ the same person frequently has charge of the execution of programs of epidemiology and of control. With the purpose of clarifying the issues an attempt has been made, as exactly as possible, to delimit both questions.

Epidemiology operates by means of investigations designed to clarify the problems of origin, evolution, and decline of leprosy; and also the establishment of endemicity. It attempts to learn the method of transmission of the disease, and all factors which favour or modify transmission.

Control seeks to eradicate the disease, employing all the facts in our possession, looking to epidemiology to furnish more and more these facts.

\section{General View.}

\section{EPIDEMIOLOGY.}

In the introduction to the Epidemiology Report of the Rio de Janeiro Conference the difficulties which are encountered in the epidemiological st

The disease has great chronicity, an infectious patient remaining so for a long period. There is also a prolonged latent period between infection and manifestation of clinical signs.

The disease cannot be transmitted to animals, and no method of cultivation of the leprosy bacillus outside the human body is available, thus precluding diagnosis during the latent period.

In the clinical field, skin manifestations must be observed over a period of years. Likewise in the collection of statistical information, such as attack rates in groups of the population varying with respect to some factor of possible significance, data must be collected over a long period of time. This necessitates the use of statistical methods now generally used in the study of other chronic diseases, such as the modified life table method. This method is especially useful in studying attack rates in leprosy households, since it takes account of births and other entrances into the households, and of deaths and other departures.

The primary task of the epidemiologist is to determine the 
magnitude of the problem in his area and to define it in such terms as will permit of comparison with other areas in his own and other countries. It is obvious, therefore, that there must be common denominators in the recognition and definition of the disease, in classification of its various types, and in the basic data which are collected regarding the individual patient and the general population of which he is a part.

When these elementary conditions are satisfied, and when necessary personnel and funds are available, the epidemiologist should turn to investigation of special topics designed to throw light on the fundamental and yet unknown factọrs which are responsible for the occurrence and spread of leprosy.

\section{Definition of Terms.}

For the purpose of establishing the frequency of leprosy in age, sex, and racial groups in different countries, and of its respective types, it is essential that the same basic indices and terminology should be used everywhere. Certain suggested indices are therefore appended to this report. Uniformity of data gathered from the whole world will allow of drawing valuable conclusions.

Leprosy Survey.

It is proposed that the name " leprosy survey" (in French: "enquete leprologique generale") be given to all the field activities of the epidemiologist. In analysing these activities, we can distinguish several operations, as follows:

(I) A preliminary procedure called a reconnaissance (termed by the Cairo Congress "extensive survey" ; in French " prospection ") of the region concerned. It consists in determining by rapid investigation, or sampling, if leprosy is present and the degree of its importance.

(2) The principal procedure is the taking of the census. This is the determination of the exact number of patients existing in the region concerned and the proportion in relation to the total population. The person in charge of the census should record a certain minimum of data, even though he may be dealing with rather primitive people. Suggested minimal data are: name or serial number, or both; age; sex: race or tribe; civil status; occupation; clinical type of leprosy.

When available, other data should be added, such as living conditions, bacteriological and immunological findings, and the numbers of children and adults exposed in the household. As suggested by the Rio de Janeiro Conferencé, the survey can be 
greatly facilitated by the establishment of permanent " skin dispensaries " and travelling clinics, at which other diseases will also be diagnosed and treated. All leprosy surveys should be accompanied by arrangements for treatment of cases discovered, and by a campaign of public education.

(3) A supplementary operation is the special inquiry, or more intensive study of special aspects of leprosy (termed by the Cairo Congress "intensive survey"). These aspect are many, including the relationship of prevalence and of type-frequency to climate, physiography of the country, ethnology, social conditions, diet, overcrowding, association with insects, tribal customs and cocxisting discases.

\section{Control.}

Control measures are considered under three divisions: (I) medical measures, (2) legal requirements, and (3) education of the public.

\section{Medical Measures.}

The campaign against leprosy must be undertaken by the coordinated action of three basic organizations: (I) leprosaria, (2) dispensaries or out-patient clinics, and (3) preventoria.

(I) Leprosaria.-A leprosarium is a place for isolation of (a) infectious patients, and (b) noninfectious patients for social, economic or other reasons. Services (medical, social, etc.) rendered to the patients should be complete and free of charge.

The most satisfactory type of leprosarium is the agricultural colony, where the patients may engage in agricultural and animalraising activities.

Another type of leprosarium to be recommended is that established on a sanatorium basis for patients with personal resources. Such patients should be subject to the same rules of prophylaxis as the nonpaying patients in the colony-leprosarium. The sanatorium may be of either governmental or private ownership, but in any case must be subject to the control of the official leprosy service.

It is recommended that the leprosarium should be situated in the proximity of an urban centre with easy means of communications. Preferably it should be within a radius of Io to $30 \mathrm{~km}$. from the nearest city. The isolation of patients on special islands is categorically condemned.

The site should be selected with a view not only to the proper functioning of the institution but also to the material and moral welfare of the inmates. The leprosarium of the colony type should 
be located in a place which lends itself, because of the soil and other natural resources, to the development of agricultural and pastoral activitics. It should, when possible, be of regional character, and with a capacity of not more than I,ooo patients.

In its organization the leprosarium should have three zones: (I) healthy zone, (2) intermediate zone, (3) patients' zone. It is recommended that there should be a minimum of one physician for every 200 patients.

Besides institutional isolation, home isolation may be permitted provided it can be guaranteed that isolation and prophylaxis will be adequate. Private isolation should not be permitted in apartment, business, or industrial buildings.

(2) Dispensaries or outpatient clinics.-Dispensaries or outpatients clinics are of fundamental importance for the control of leprosy. They should be regional and located in areas of greatest density of population, with suitable communication facilities. They should be adequately provided with personnel, material, and means of transportation in order to fulfil their purposes, which are:

(a) finding of cases and segregation of infectious ones; (b) epidemiological investigations; (c) selection of cases for isolation; (d) control and treatment of non-isolated cases, including those paroled from leprosaria; (e) control of suspects; (f) control of contacts; (g) control of absconders; (h) removal to preventoria of children of infectious parents when necessary; (i) sanitary educa tion; (j) disposal of cases for final discharge.

The control of contacts should be carried out in accordance with modern concepts, with special reference to the lepromin reaction. On that basis, contacts should be divided into two groups: lepromin negative and lepromin positive.

Contacts with negative and weakly-positive lepromin reactions should be given special attention. They should be re-examined every six months for five years, counting from the last known contact, however slight, with an infectious case.

Contacts giving strongly positive lepromin reactions may be re-examined at longer intervals, and the period of observation may be decreased at the discretion of the health authorities.

(3) Preventoria.-The preventorium is designed to care for the minor dependents of patients under isolation. By preference. it should be located within a city or in its immediate vicinity. This will facilitate the functioning of the institution, the provision of efficient medical and sanitary services, and progressive adaptation of the inmates to society. 
Modern clinical and immunological concepts of leprosy indicate that children with the bacteriologically-negative tuberculoid and indeterminate forms may be permitted to remain in the preventorium: likewise lepromin-positive children paroled from leprosaria. It is recommended, however, that this concession be granted only in institutions where medical control is regular and efficient.

Separate from the pavilions housing the ordinary inmates, there should be an observation pavilion for suspects and cases, such as those mentioned above. It is also recommended that recently admitted children be accommodated in a special ward for a period of not less than three weeks.

Children living in the preventorium should be submitted to periodical examinations, the duration and frequency of which would depend on their state of resistance as indicated by the lepromin reaction

The institution should have a nursery for the care of the newlyborn infants of leprosy patients. This section might be located in the preventorium itself, or outside of it.

\section{Preparation of technical personnel.}

It should be emphasized that it is not possible to develop a campaign against leprosy without specially trained technical personnel. It is recommended that physicians, nurses, laboratory technicians and attendants should be given courses of leprology and practical training in the leprosy-control services or establishments. To official institutions for the control of leprosy it is also recommended that the category of leprologist should be created, with adequate remuneration, as a necessary incentive to the attainment of technical efficiency.

In countries where leprosy is endemic, it is of the greatest importance that the teaching of leprology in the dermatological clinics should be emphasised. It should also be included in public health courses.

Governments should maintain, or aid, the operation of institutes of leprology dedicated to scientific investigations in the epidemiology, therapy and pathology of leprosy, as well as the proper training of technical personnel.

\section{LEGAL REQUIREMENTS.}

General recommendation. Laws for the control of leprosy enacted by legislative bodies should embody only general principles and the necessary authorizations. The regulations to be established should be made by experts, and should be revised 
periodically in accord with the progress of epidemiological knowledge.

Specific recommendations. - (a) In all countries where leprosy is endemic, medical students should be given adequate instruction regarding the disease, to provide for its early diagnosis and notification.

(b) Governments should initiate the necessary investigations to acquire as complete a knowledge as possible of the number of leprosy patients, this being an indispensable basis for prophylaxis.

(c) Infective cases of leprosy should be isolated. The mode and duration of isolation will vary, depending upon the clinical and social conditions of the patient and special local conditions.

(d) Wherever possible, adequate treatment should be provided for all cases, whether isolated or not.

(e) Governments are strongly urged to provide, for isolated patients, the standards of comfort and amenities to which they are entitled. They should be given opportunities to improve their condition by their own work, or to use their own resources.

$(f)$ Governments are urged to provide directly or indirectly the necessary means of subsistence for nonself-supporting dependants of leprosy patients.

$(g)$ Recognising that bad hygienic conditions of housing and living in large communities contribute to the spread of leprosy, governments are recommended to make all possible efforts to improve such conditions, in accordance with local possibilities.

(b) Non-infectious patients, not isolated, should be kept under regular and periodic supervision.

(i) Regular and periodic observation is also of the utmost importance for those who are or have been in direct contact with patients.

(j) Separation of children from infective patients should be made immediately after birth, or as soon as the diagnosis of leprosy in the parent or the person who is " in loco parentis " is made.

(k) For the termination of isolation of infective cases and the supervision of non-isolated cases the clinical, bacteriological and immunological conditions should be taken into account. In the supervision of contacts, immunological conditions should be taken into account.

(l) Propaganda for non-scientific remedies by interested persons represents a serious impediment to the control of leprosy and should be curtailed by governments. 
( $m$ ) It is recommended that co-operative agreements be made between neighbouring governments for the interchange of information designed to permit the continuance of supervision of patients and contacts and the prevention of the illegal passage of patients from one country to another.

\section{Education of the General Public.}

For educational purposes the public may be divided into three classes: (I) the general public, (2) the selected public, and (3) contacts of leprosy patients.

Propaganda should be carried on through the press, radio, leaflets, etc., referring to the advantage of the examination of everyone with skin diseases or disturbances of cutaneous sensation. The examinations should be made in public dermatology clinics or in private offices of dermatologists. The same propaganda should stress the danger of consulting quacks, or unlicensed doctors; also the use of patent medicines, etc., which may prove harmful.

It should be emphasized that leprosy is infectious and contagious, but avoidable. Its control involves precautions and restrictions which vary in different regions, but need not be excessive. Only " open " cases require isolation. The period of isolation depends upon the progress of the disease and its response to treatment. Leprosy is frequently curable and most likely to be if treated early, provided the treatment is supervised by adequately trained physicians and is taken regularly by the patients. Modern drugs promise to be more effective than those available in the past.

It is necessary for the educational campaign to secure the help of different organizations which influence public opinion, such as professional, civic, religious and missionary organizations, press associations and organizations of authors, the radio broadcasting and moving-picture industries, etc. The essential points to bring out are:

(a) To avoid the use of the word "leper " and other undesirable terms.

(b) To correct the present error of public opinion that leprosy is a biblical scourge and that the patient is cursed. This error brings stigma and injury to the patient, makes him conceal his disease, prevents him from seeking medical assistance, and increases the danger to the public.

(c) We deprecate all publicity in newspapers, magazines. novels, movies, etc., and all other situations in which leprosy and the patient are dramatized, when the presentation does not agree with modern knowledge. 
Household contacts should receive instruction regarding the nature of the disease, stressing particularly:

(a) the advantages of an early general medical examination;

(b) the advantages of successive and periodical examinations;

(c) the importance of personal and household hygiene.

\section{APPENDIX. RECOMMENDED INDICES.}

1. The Morbidity Prevalence Rate or Prevalence Index.

This rate should be as recommended by the Rio de Janeiro Conference, viz: The number of cases of leprosy existing in $a$ population at a specific date:

$$
\text { M.P.R. }=\frac{\text { Number of cases of leprosy } \mathrm{x} \text { Iooo }}{\text { Total enumerated population }}
$$

2. The Morbidity Incidence Rate or Incidence Index.

This index is required to learn the trend of the disease. In areas where the census is repeated, it will be possible to compute an estimated annual incidence rate: that is, the number of new cases appearing in the population during a period of one year:

Annual M.I.R. = Number of new cases in a year $\mathrm{x}$ Iooo

$$
\text { Total enumerated population }
$$

NOTE: Wherever it is possible to classify the cases according to type, both the M.P.R. and the M.I.R. should be broken down (sub-divided) by type of the disease. In calculating the rates for specific types, the denominator should be as for total prevalence and incidence; that is, the total enumerated population of the area, village, city or country.

It will be noted that if the average duration of the disease, ketween recognition and death, is for example ten years, and if the total prevalence of the disease is five per Iooo, we must have an average annual incidence (M.I.R.) of five per Io,000.

$$
\begin{aligned}
& \text { Prevalence-incidence } \mathrm{x} \text { duration (years) } \\
& \text { or } \frac{5}{1000}=\frac{5}{10,000} \quad x \text { Io }
\end{aligned}
$$

It will also be noted that, if the repeated censuses are fairly accurate, the duration of the disease may be estimated from the M.P.R. and the M.I.R.m because:

$$
\begin{aligned}
\text { Duration }= & \text { Prevalence } \\
& \text { Incidence }
\end{aligned}
$$

3. The Childhood Rates.

(a) The prevalence rate for children (childhood prevalence 
rate) recommended by the Rio de Janeiro Conference should be aclopted viz:

The number of cases in children under I5 years of age $\mathrm{x}$, 1000

The number of enumerated children under 55 years of age

(b) Likewise, when censuses are repeated, the anmul childbood incidence rate, which is most important, should be estimated, viz.: The number of new cases in children under 15 years of age $\mathrm{x}$ IOOO

The number of enumerated children under I5 years of age

NOTE: It is desirable to break down prevalence and incidence rates in children by sex and type.

4. The Adult Rates.

(a) Prevalence:

Number of cases in persons over I5 years of age $\mathrm{x}$ I000

Number of enumerated persons over 15 years of age

(b) Incidence:

Number of new cases in persons over I5 years of age $\mathrm{x}$ I000

Number of enumerated persons over I5 years of age

NOTE: It is desirable to break down both prevalence and incidence rates by sex and type.

\section{Household Contact Rates.}

Similarly, prevalence and incidence rates for children o to I5 years of age and for adults 15 years and more may be obtained in special long-time studies for persons exposed in the household to different types of leprosy. The difficulties of accurate studies of this type are recognized, and the advantages of the modified life table method are emphasized.

\section{APPENDIX II. RESOLUTION.}

Proposed by the Committee on Epidemiology and Control that the Congress give recognition to the importance of enforcing laws governing national campaigns against leprosy; express commendation to Colombia, Egypt, Portugal and Norway for having accomplished this within the last 2 years; and resolve that these regulitticns should be published in the Transactions of the Congress.

(This resolution, submitted separately, did not find its way into the Committee report as presented at the Plenary Session and consequently was not acted upon.-Ed.). 


\section{REPORT ()F THE COMMITTEE ON CIASSSIFICATION AND NOMENCLATURE}

\section{INTRODUCTION."}

The great diversity in the forms of leprosy has led to many attempts to establish systems of classification. Hansen and Looft put forward a well founded division into two types. The first attempt to establish an internationally acceptable formula of classification was made hy the Leonard Wood Memorial Conference, held in Manila I93I. The classification then put forward - which was primarily clinico-anatomical including the bacteriological factor and to a certain extent the histopathology-was amplified and extended by the International Congress held in Cairo in 1938; and that system still prevails in many parts of the world

Previous to that time attempts had been made, by a group which, constituted a minority at the Cairo Congress, to expand the basis of classification. More emphasis than previously was laid upon the histopathological characteristics, and the immunological factor as represented by the lepromin reaction was introduced. It had long been felt that any satisfactory classification must be a natural one taking into account the greatest possible number of facts and establishing the most homogeneous categories possible; and that these categories must be based on essential and constant characteristics. The efforts of this group led to the development of the South American Classification, which was designated the Pan-American Classification at a conference held in Rio de Janeiro I946.

The Classification Committee of this Congress, in a serious attempt to reconcile and unify these apparently discordant systems, has arrived at a formula which is believed to be based on a biologic interpretation of the clinical facts. The criteria on the basis of which the three classes herein defined are established are, in diminishing order of availability: (I) clinical, (2) bacteriological, (3) immunological, and (4) histopathological.

It is proposed that the classical division of leprosy into two types "polar" (Rabello, I938) in their essential characteristics and relatively stable in their evolution, be recognised and maintained, and that they be designated:

Lepromatous (malignant, or gravis): symbol, L.

Tuberculoid (benign, or mitis): symbol, $\mathrm{T}$.

It is also proposed that, in addition, recognition be given a 
group of cases of less distinctive or positive characteristics less stable and less certain with respect to evolution, and that it be designated: Indeterminate (undifferentiated) symbol, I.

\section{DeFinitions.}

The characteristics of these three classes of leprosy are as follows:-

Lepromatous type. Minimal resistance to the existence, multiplication and dissemination of the bacilli; constant presence of large numbers of bacilli in the lesions, with a distinctive tendency to form globi; characteristic clinical manifestations in the skin, mucous membranes (especially of the upper respiratory tract and eye), and/or the peripheral nerves, together with involvement of other organs; regular failure to react to lepromin; pathognomic granulomatous structure of the lesions; marked stability of type and a tendency to progression. These cases are "infectious" or " open."

Tuberculoid type. High resistance to the existence, multiplication and dissemination of the bacilli; bacteriologically negative as a rule or, if positive, with few bacilli except in reactional states: characteristic clinical manifestations, mainly in the skin and nerves, tending to be limited in extent and varying in degree with the reactivity of the tissue; reactivity to lepromin in a very high percentage of cases; nearly always a tuberculoid granulomatous structure in active lesions: marked stability, and a strong tendency to spontaneous regression in the absence of repeated reactions. These cases are usually, "non-infectious " or " closed."

Indeterminate group. Variable with respect to resistance, clinical manifestations chiefly in the skin and nerves; the skin lesions usually flat macules, either hypochromic, erythematohypochromic or erythematous; bacteriologically negative as a rule or, if positive, with few bacilli; lepromin reaction usually negative or moderately positive; the lesions histologically of simple inflama. tory nature; stability much less than in either of the polar types; and a variable tendency with regard to persistence, progression or regression, or transformation into one of the polar types. These cases are usually ' non-infectious.'

\section{Clinical Subdivision of Cases.}

The fundamental aim of any classification of a leprosy case being the determination of the type or group to which it belongs. in accordance with the foregoing definitions, certain members of the Classification Committee held that the "subtypes" of other 
systems merely correspond to clinical aspects of variable importance. These aspects can be considered from different points of view, namely:

Degree of severity (as, for example, the $\mathrm{L}_{1}, \mathrm{~L}_{2}, \mathrm{~L}_{3}$, of the Memorial Conference classification);

Manner of evolution (slow or rapid, stationary or progressive, reactional states, etc.);

Localization (skin, nerve, eye, systemic, etc.);

Morphology (macules, nodules, " plaques," diffuse infiltrations, etc);

Clinical formi (classical nodular lepromatous, diffuse lepromatosis of Lucio, etc.).

(Fhe rest of the report of the Classification Committee, adopted by it with minority disagreement, comprised a suggested scheme of subtyping cases, with names and definitions, and a section on reactional condition. That part of the report was rejected by the Congress. A proposed appendix setting forth details of investigative procedures was not considered at all.-Ed.)

\section{REPORT ON \\ THE WORDS “LEPER ” AND “LEPROSY”}

It is agreed:

(I) That the use of the term "leper" in designation of the patient with leprosy be abandoned, and the person suffering from the disease be designated ' leprosy patient.'

(2) That the use of any term, in whatever language, which designates a 'person suffering from leprosy' and to which unpleasant associations are attached, should be discouraged. However, the use of the name "leprosy" should be retained as the scientific designation for the disease. Active steps should be taken to explain fully to the general public its real nature.

(3) That if the regional popular use of any less specific ternıs, in substitution for the scientific name "leprosy," enables the general public to understand more fully and clearly the advances that have been made in the understanding, diagnosis and treatment of the disease, such terms may be used as suitable opportunity offers; but it would be unwise to adopt such terms to conceal the true nature of the disease.

(4) That these conclusions should be communicated to scientific journals and the press. 


\section{REPORT ON SOCIAL ASSISTANCE}

Social assistance of the patient with leprosy and of his family is a fundamental necessity in combating this disease. Governments and voluntary organizations are therefore urged to accept responsibility for providing such assistance.

A "Social Assistance" program should include:

(I) Provision of special institutions to enable healthy children of leprosy patients to live. a normal active life, under the supervision of trained leprologists.

(2) Assistance of the families of leprosy patients to maintain their position in society without fear of ostracism.

(3) Provision of facilities for the education, occupation, recreation and devotional life of patients with leprosy.

(4) Assistance in the rehabilitation of those who are able to leave the leprosaria.

(5) Health education, with particular reference to the leprosy prot' $\mathrm{m}$. 